\title{
In-Source H/D Exchange and Ion-Molecule Reactions Using Matrix Assisted Laser Desorption/Ionization Fourier Transform Ion Cyclotron Resonance Mass Spectrometry with Pulsed Collision and Reaction Gases
}

\author{
Matthias Witt, Jens Fuchser, and Gökhan Baykut \\ Bruker Daltonik GmbH, Bremen, Germany
}

\begin{abstract}
Controlled in-source ion-molecule reactions are performed for the first time in an external matrix assisted laser desorption ionization (MALDI) source of a Fourier transform ion cyclotron resonance mass spectrometer. The MALDI source with a hexapole ion guide that was originally designed to incorporate pulsed gas to collisionally cool ions (Baykut, G.; Jertz, R.; Witt, M. Rapid Commun. Mass Spectrom. 2000, 14, 1238-1247) has been modified to allow the study of in-source ion-molecule reactions. Upon laser desorption, a reaction gas was introduced through a second inlet and allowed to interact with the MALDI-generated ions trapped in the hexapole ion guide. Performing ion-molecule reactions in the high pressure range of the ion source prior to analysis in the ion cyclotron resonance (ICR) cell allows to maintain the ultra high vacuum in the cell which is crucial for high mass resolution measurements. In addition, due to the reaction gas pressure in the hexapole product ion formation is much faster than would be otherwise possible in the ICR cell. H/D exchange reactions with different peptides are investigated, as are proton-bound complex formations. A typical experimental sequence would be ion accumulation in the hexapole ion guide from multiple laser shots, addition of cooling gas during ion formation, addition of reaction gas, varied time delays for the ion-molecule reactions, and transmission of the product ions into the ICR cell for mass analysis. In this MALDI source H/D exchange reactions for different protonated peptides are investigated, as well as proton-bound complex formations with the reaction gas triethylamine. Amino acid sequence, structural flexibility and folding state of the peptides can be seen to play a part in the reactivity of such ions. (J Am Soc Mass Spectrom 2002, 13, 308-317) (C 2002 American Society for Mass Spectrometry
\end{abstract}

$\mathrm{T}$ The development of electrospray ionization (ESI) [1-5] and matrix assisted laser desorption ionization (MALDI) [6-9] has provided mass spectrometry (MS) with two very important tools for investigating biomolecules in the gas phase. ESI and MALDI are fairly mild ionization processes, generally involving cation transfer (usually a proton), that generates positive or negative gas-phase ions while retaining the structural integrity of the analyte. More and more structural information of peptides is emerging from gas-phase studies utilizing mass spectrometry.

MALDI has become one of the fastest growing techniques in mass spectrometry due to its application to biological and biochemical research [9-14]. Fourier transform ion cyclotron resonance mass spectrometry (FT-ICR MS) [15-20] is known for its unparalleled mass

Published online February 7, 2002

Address reprint requests to Dr. G. Baykut, Bruker Daltonik GmbH, Fahrenheitstrasse 4, 28359 Bremen, Germany. E-mail: gb@bdal.de accuracy and mass resolution and has become an important tool in many areas of analytical life sciences [21, 22]. For this reason, the FT-ICR MS technique has been combined with the soft ionization technique MALDI using internal [23-28] as well as external [29-37] ion sources. One of the striking advantages of the MALDI FT-ICR technique is high sensitivity as well as high throughput capability.

Many ion chemistry studies show similarities between the behavior of gas-phase ions and equivalent species in the condensed phase [38, 39]. As the amount of structural information emerging from gas-phase ion studies increases, MS techniques, particularly in combination with $H / D$ exchange reactions, are playing an increasingly important role in structural analysis of biomolecules [40-47]. H/D exchange reactions are studied by allowing deuterated reaction partners to interact with protonated functional groups of for instance polypeptides and proteins, sequentially replacing the protons with deuterons. The rate of exchange is 
related to the reactivity of each particular site. In a recent example, Freitas et al. carried out H/D exchange reactions using FT-ICR MS with ESI in order to prove the existence of zwitter-ions of protonated bradykinin in the gas phase [48].

The advantage of measuring H/D exchange experiments [49-51] in an external ion source with FT-ICR MS has recently been demonstrated by Hofstadler et al. who used a modified ESI source where reaction gas was pulsed into the area of the hexapole ion guide of the ESI source $[52,53]$. By accumulating ESI-generated ions in this hexapole allowing them to undergo ion-molecule reactions, no reaction gas was required in the ICR analyzer cell. Removal of the pulsed gas from the analyzer region would require extra pumping times as in collision induced dissociation (CID) experiments. Thus, products of the in-source ion-molecule reactions [54] (e.g., H/D exchange reactions, deprotonation or complex formation) can be detected without disturbing the ultra high vacuum (UHV), which would in turn affect the supreme mass resolution. Furthermore, product ions are formed much faster in the hexapole ion guide of the ion source than in the ICR cell because of the reaction gas pressure greater than $10^{-3}$ mbar.

Basic design and the construction details of the low voltage medium pressure MALDI source for FT-ICR MS with in-source collision gas and in-source ion accumulation capability has recently been reported elsewhere [36]. This external MALDI source is equipped with a hexapole ion guide and a pulsed gas inlet, both in direct proximity to the laser target. During their generation, ions are cooled using a pulsed collision gas which reduces the ion kinetic energy spread that results from the MALDI process. Simultaneously, they are captured in the hexapole ion guide. Additional cooling of ions in the hexapole can be achieved while they are trapped in the hexapole using further collision gas pulses. Continued developments of the sample handling system, the hardware for computer controlled target $\mathrm{x} / \mathrm{y}$-positioning, laser and observation optics, as well as the operation software with the FT-ICR have led to a completely computer-controlled MALDI source with a hexapole ion trap and pulsed collision gas (Figure 1).

Due to the continuous nature of the electrospray process, ions steadily enter the hexapole ion guide of the ESI source. Following a pulsed event extracting ions out of the hexapole, accumulated ions are injected into the ICR cell. The MALDI process, however, produces ions in a discontinuous way such that every laser pulse generates a certain number of ions that are captured and accumulated in the hexapole ion guide. This simplifies the kinetics as an additional time spread is eliminated during the reaction time. This is different in the conventional ESI sources which have additional time spread, as the hexapole is continuously filled during the ion-molecule reaction. Gated beam techniques have been introduced in some ESI sources by using shutter interrupting the continuous stream of ions

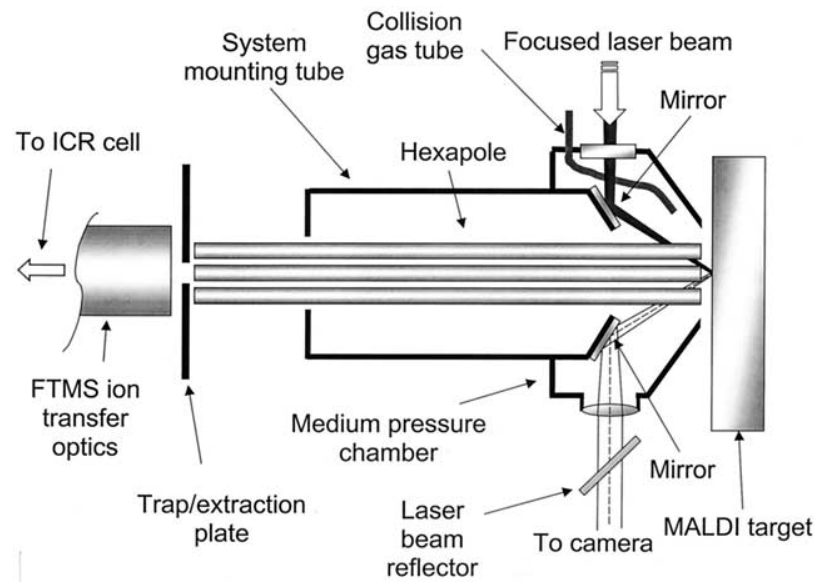

Figure 1. Schematic drawing of the SCOUT 100 MALDI source. The laser beam enters the medium pressure chamber from the side passing through a quartz window and is then reflected to the laser target. The pulse gas tube is directed to the point where the laser hits the target. The observation optics views the target from the opposite side. A laser beam reflector protects the camera from laser radiation scattered from the target. The tube on which the medium pressure chamber is mounted further covers the system so that a large part of the hexapole is under elevated pressure if collision gas is pulsed or a reaction gas is introduced.

so that the process in the hexapole can be studied more accurately [55-58].

For all MALDI source reactions described herein, all ions of a certain experiment have the same time to react. The experiment starts with the collision gas pulse and the laser shots. After the laser is stopped, the reaction gas is introduced. During ion generation (MALDI) event no reaction occurs as there is no reaction gas present. During the reaction period no new MALDI ions are generated, as the laser is not in operation.

To demonstrate the benefit of external ion-molecule reactions with MALDI-generated ions, the ion source was modified by introducing a second pulsed gas inlet (Figure 2). In this way, it is possible to ensure a cooling of the reacting ions via the first pulsed valve as well as a constant reaction gas pressure through the second pulsed valve.

\section{Experimental}

\section{Apparatus}

The construction details of the MALDI source used in this paper have been described in detail elsewhere [36]. Further improvement of the source includes a 100 spot target $(10 \times 10$ geometry $)$, which can be moved in the xy-plane by software control. All loading processes are also software controlled as is the laser power.

This external MALDI source has been flanged to the source chamber of an APEX II FT-ICR MS from Bruker Daltonics (Billerica, MA) equipped with an actively shielded 7T super-conducting magnet. In this system, the ICR cell is a cylindrical infinity cell [59] with equipotential-line-segmented trapping plates. The pres- 


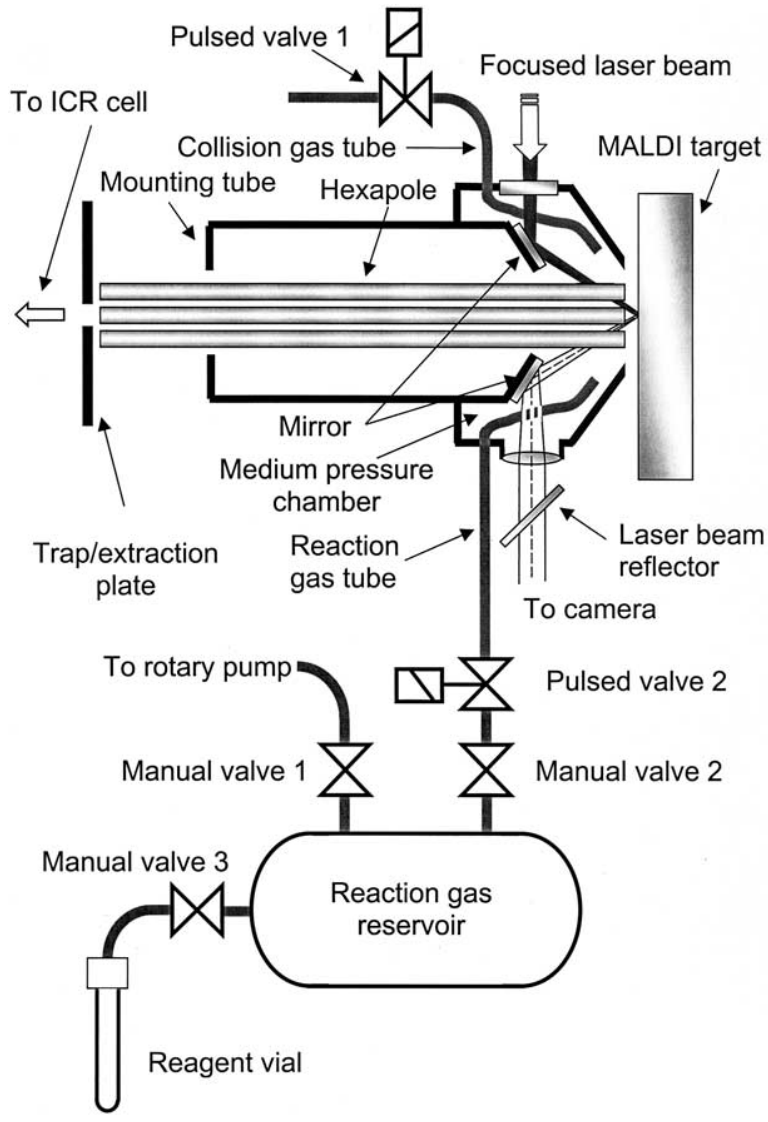

Figure 2. The additional reaction gas tube, the reaction gas reservoir as well as the complete setup for ion-molecule reaction studies in the MALDI source are depicted in this schematic drawing.

sure in the FT-ICR MS source chamber is in the range of $10^{-6}$ to $10^{-7}$ mbar. For cooling the ions the pressure in the proximity of the MALDI target is increased by pulsing argon through a stainless steel tube $(0.8 \mathrm{~mm}$ i.d.) with a solenoid pulse valve from Parker Hannifin (Cleveland, $\mathrm{OH}$ ) in a partially isolated volume inside

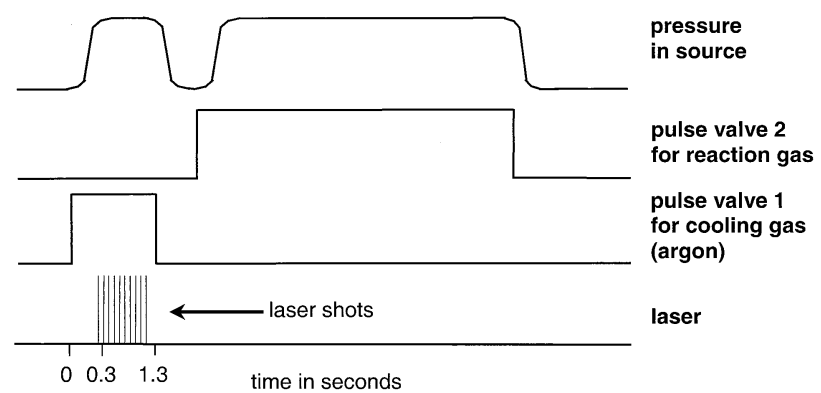

Figure 3. Event sequence in the MALDI experiments for the cooling gas pulse valve and reaction gas pulse valve with a schematic display of the pressure change in the MALDI source.

the medium pressure chamber (MPC), as shown in Figure 1. For ion-molecule reaction studies, this chamber is now also equipped with a second identical stainless steel tube, which itself is connected to a second solenoid pulse valve in order to transfer the reaction gas to the direct vicinity of the laser target. The reaction gas was stored in a reservoir, which consists of three leak valves, a heating device, and a connector to a glass vial containing the liquid reactant (Figure 2). For evacuating the reservoir Valve 1 was connected to a rotary pump. Valve 2 was connected to the ion-source, Valve 3 was between the glass vial and the reaction gas container.

The MPC is pumped through a tube connected to the FT-ICR MS source chamber. A turbo-molecular pump EXT 501 manufactured by BOC Edwards High Vacuum (Crawley, UK) with a pumping speed of $500 \mathrm{~L} / \mathrm{s}$ is used in the source chamber of the APEX II FT-ICR MS system. An infrared multiphoton dissociation (IRMPD) equipment from Bruker Daltonics containing a $\mathrm{CO}_{2}$ laser J48-2 with $25 \mathrm{~W}$ power output from Synrad (Mukilteo, WA) for multiphoton dissociation of ions was installed at the back of the magnet. The laser beam was aligned to irradiate through the ICR cell.

Table 1. Compounds used for $H / D$ exchange measurements as well as the results of $H / D$ exchange experiments for $C D_{3} O D$ and $\mathrm{D}_{2} \mathrm{O}$ at a reading pressure of $8.3 \times 10^{-6}$ mbar and $2.0 \times 10^{-6}$ mbar after $60 \mathrm{~s}$ reaction time, respectively

\begin{tabular}{|c|c|c|c|c|c|}
\hline Compound & $\begin{array}{l}\text { Molecular } \\
\text { formula } \\
{[\mathrm{M}+\mathrm{H}]^{+}}\end{array}$ & $\begin{array}{c}\text { Theoretical } \\
\text { monoisotopic } \\
\text { mass } \\
{[\mathrm{M}+\mathrm{H}]^{+}}\end{array}$ & $\begin{array}{l}\text { Maximum } \\
\text { possible H/D } \\
\text { exchanges }\end{array}$ & $\begin{array}{c}\text { Maximum } \\
\text { observed } \mathrm{H} / \mathrm{D} \\
\text { exchanges with } \\
\mathrm{CD}_{3} \mathrm{OD}\end{array}$ & $\begin{array}{c}\text { Maximum } \\
\text { observed } \mathrm{H} / \mathrm{D} \\
\text { exchanges with } \\
\mathrm{D}_{2} \mathrm{O}\end{array}$ \\
\hline Angiotensin I (1) & $\mathrm{C}_{62} \mathrm{H}_{90} \mathrm{~N}_{17} \mathrm{O}_{14}$ & 1296.685 & 20 & $13(65 \%)^{a}$ & Not measured \\
\hline Angiotensin II (2) & $\mathrm{C}_{50} \mathrm{H}_{72} \mathrm{~N}_{13} \mathrm{O}_{12}$ & 1046.542 & 17 & $11(65 \%)$ & Not measured \\
\hline Angiotensin III (3) & $\mathrm{C}_{46} \mathrm{H}_{67} \mathrm{~N}_{12} \mathrm{O}_{9}$ & 931.515 & 15 & $10(67 \%)$ & Not measured \\
\hline Bradykinin (4) & $\mathrm{C}_{50} \mathrm{H}_{74} \mathrm{~N}_{15} \mathrm{O}_{11}$ & 1060.569 & 18 & $14(78 \%)$ & $15(83 \%)$ \\
\hline Met-Lys-Bradykinin (5) & $\mathrm{C}_{61} \mathrm{H}_{95} \mathrm{~N}_{18} \mathrm{O}_{13} \mathrm{~S}$ & 1319.704 & 22 & $20(91 \%)$ & $19(86 \%)$ \\
\hline LHRH free acid (6) & $\mathrm{C}_{55} \mathrm{H}_{75} \mathrm{~N}_{16} \mathrm{O}_{14}$ & 1183.564 & 19 & $10(53 \%)$ & $9(47 \%)$ \\
\hline LHRH amide (7) & $\mathrm{C}_{55} \mathrm{H}_{76} \mathrm{~N}_{17} \mathrm{O}_{13}$ & 1182.580 & 20 & $6(30 \%)$ & $6(30 \%)$ \\
\hline Substance $P(\mathbf{8})$ & $\mathrm{C}_{63} \mathrm{H}_{99} \mathrm{~N}_{18} \mathrm{O}_{13} \mathrm{~S}$ & 1347.735 & 19 & $18(95 \%)$ & $18(95 \%)$ \\
\hline $\begin{array}{l}\text { Substance } P \\
\quad \text { fragment } 4-11(9)\end{array}$ & $\mathrm{C}_{46} \mathrm{H}_{68} \mathrm{~N}_{11} \mathrm{O}_{10} \mathrm{~S}$ & 966.487 & 15 & $0-1(<6 \%)$ & $0-1(<6 \%)$ \\
\hline Cyclosporin (10) & $\mathrm{C}_{62} \mathrm{H}_{112} \mathrm{~N}_{11} \mathrm{O}_{12}$ & 1202.849 & 5 & 0 & Not measured \\
\hline
\end{tabular}

aPercentage of $\mathrm{H} / \mathrm{D}$ exchange in brackets. 


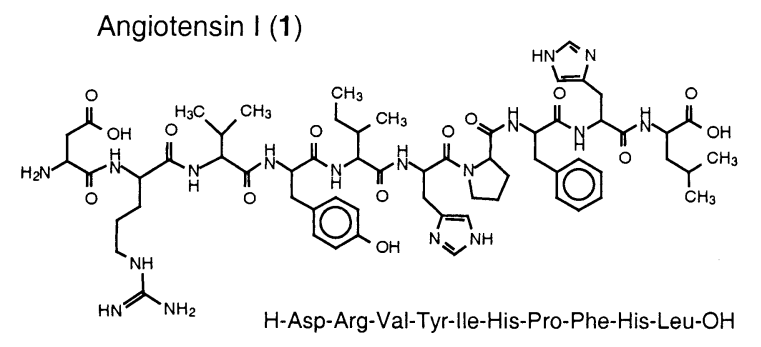

Angiotensin II (2)

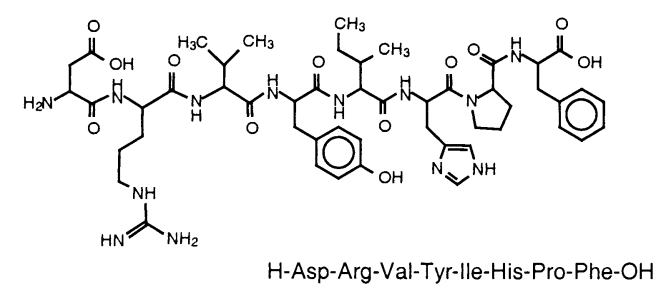

LHRH free acid (6)

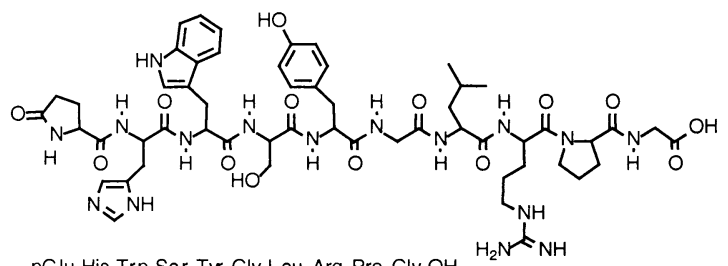

pGlu-His-Trp-Ser-Tyr-Gly-Leu-Arg-Pro-Gly-OH $\mathrm{H}_{2} \mathrm{~N}-\mathrm{NH}$

Angiotensin III (3)
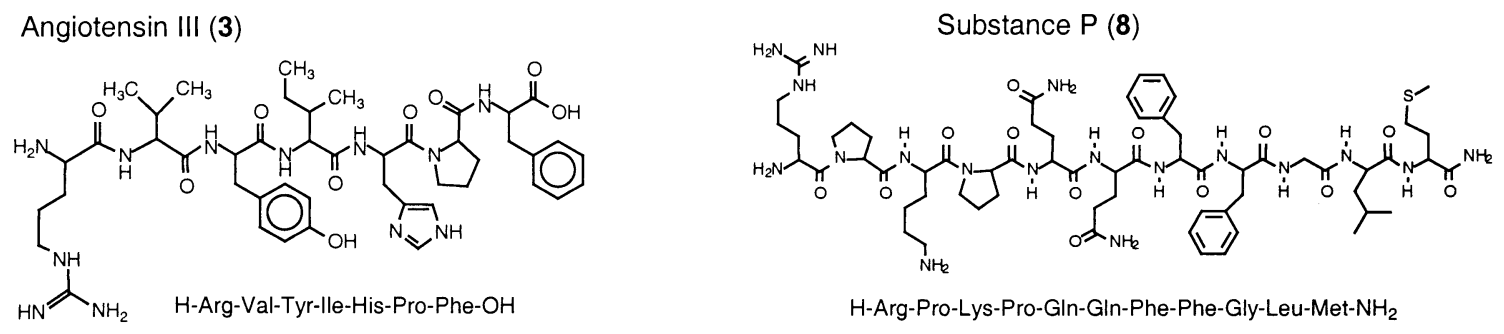

Bradykinin (4)

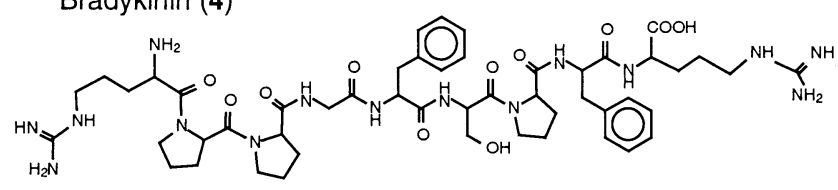

H-Arg-Pro-Pro-Gly-Phe-Ser-Pro-Phe-Arg-OH

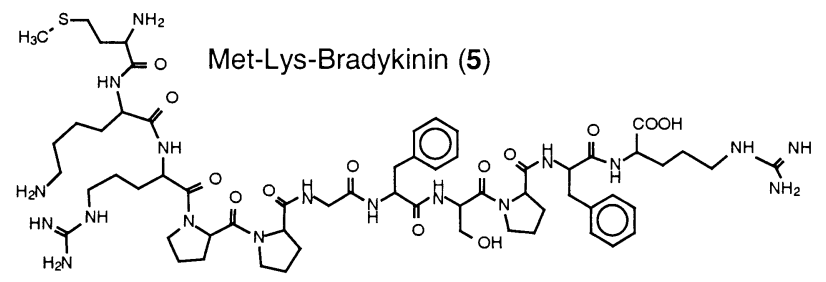

H-Met-Lys-Arg-Pro-Pro-Gly-Phe-Ser-Pro-Phe-Arg-OH

$\left(-\mathrm{Xaa}^{1}-\mathrm{Abu}^{2}-\mathrm{Sar}^{3}-\mathrm{MeLeu}^{4}-\mathrm{Val}^{5}-\mathrm{MeLeu}^{6}-\mathrm{Ala}^{7}-\mathrm{D}-\mathrm{Ala}^{8}-\mathrm{MeLeu}^{9}-\mathrm{MeLeu}^{10}-\mathrm{MeVal}{ }^{11}\right.$-) $\mathrm{Xaa}=3$-hydroxy-4-methyt-2-methylamino-6E-octenoic acid
$\mathrm{Abu}=2$-amino butanoc acid

Scheme 1 Structures of Compounds 1-10.

\section{Operation}

The event sequence (Figure 3) in the MALDI experiment was started by opening pulse Valve 1 so as to increase the pressure in the proximity of the laser target. A delay time of $0.3 \mathrm{~s}$ was set between the activation of the pulse valve and the laser pulses to allow the pressure to build up in the MALDI target region. After this delay, the laser was fired with a repetition rate of 20 $\mathrm{Hz}$ while pulse Valve 1 remained open. Thus, depending on the number of shots, the desired number of ions 


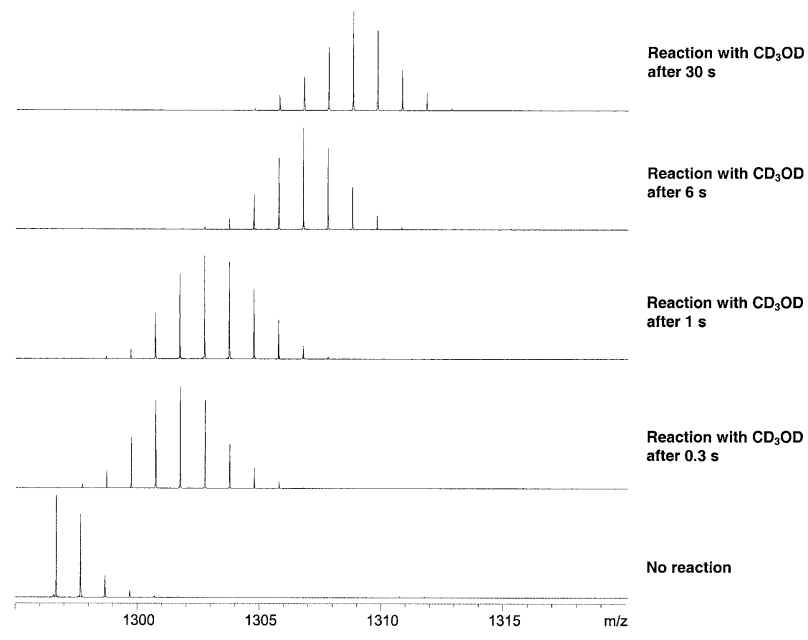

Figure 4. Reaction of $[1+\mathrm{H}]^{+}$with $\mathrm{CD}_{3} \mathrm{OD}$ at a reading pressure of $8.3 \times 10^{-6}$ mbar in the MALDI source after various reaction times.

could be stored and cooled in the hexapole prior to reaction. The pulse width of Valve 1 was usually set to $0.5 \mathrm{~s}$, resulting in a reading of $5 \times 10^{-5}$ mbar on the pressure gauge connected to the source chamber of the FT-ICR mass spectrometer. The actual local pressure in proximity of the laser target is expected to be higher, e.g., in the $10^{-2}$ mbar region. Because of the way in which the hexapole ion guide and the MALDI MPC have been mounted, a pressure gradient is known to exists along the hexapole ion guide. However, for all compounds studied with deuterated reagents $\left(\mathrm{D}_{2} \mathrm{O}\right.$ or $\mathrm{CD}_{3} \mathrm{OD}$ ), the $\mathrm{H} / \mathrm{D}$ exchange experiments have been carried out at the same reactant gas pressure and studied during comparable reaction times. Additionally, all compounds studied fell into approximately the same mass range (around $m / z$ 1000). So, the experimental H/D exchange results for all compounds can be compared. For all experiments described herein a fixed pumping delay time of $0.5 \mathrm{~s}$ was used before the reaction gas was pulsed in the hexapole region via the second pulse valve (Figure 2). All reactants were degassed employing multiple freeze-pump-thaw cycles. The pressure readings in the reaction gas containers prior to reaction were $12 \mathrm{mbar}, 15 \mathrm{mbar}$, and $4 \mathrm{mbar}$ for the reactants $\mathrm{D}_{2} \mathrm{O}, \mathrm{CD}_{3} \mathrm{OD}$, and $\mathrm{N}\left(\mathrm{C}_{2} \mathrm{H}_{5}\right)_{3}$, respectively. The experiments have been carried out at room temperature without any further temperature control of the source chamber.

A variable delay was inserted after the second pulse event for varying reaction times. Reactions were terminated by an extraction pulse changing the polarity of the extraction plate and thus extracting the ions out of the hexapole and transferring them into the ICR cell.

Scans were performed in the $\mathrm{m} / \mathrm{z}$ range from 790 to 2000 at a sweep width of $137 \mathrm{KHz} .512 \mathrm{~K}$ data points were acquired resulting in an acquisition time of 1.91 $\mathrm{s} /$ scan. The points in H/D exchange profiles $5 \mathrm{a}-\mathrm{d}$ have been calculated from maxima of the envelopes of the isotopic patterns in mass spectra. No deconvolution considering carbon isotopes has been carried out. Thus, a slight shift of the maximum is always included in the isotopic distribution resulting in a small error of the H/D exchange profiles. Since compounds with very similar number of carbon atoms have been studied here, the error due to the ${ }^{13} \mathrm{C}$-shift of the data points of the $\mathrm{H} / \mathrm{D}$ exchange profiles is negligible for the data analysis and conclusion. The decomposition of the proton-bound heterodimer of the substance $\mathrm{P}$ fragment 4-11 (9) and triethylamine was accomplished by IRMPD with various irradiation times up to $150 \mathrm{~ms}$ using a $\mathrm{CO}_{2}$ laser with a wavelength of $10.6 \mu \mathrm{m}$ and a power setting of $50 \%$ (for details see discussion).

\section{Sample Preparation}

The matrix 2,5-dihydroxybenzoic acid (DHB) was used for all analytes described in this work. A $100 \mathrm{mg} / \mathrm{ml}$ solution of DHB in a standard solvent consisting of acetonitrile, water (30:70 vol:vol), and $0.2 \%$ trifluoroacetic acid was prepared. The analytes were dissolved in this standard matrix solution and subsequently diluted with it. 0.25 to $1 \mu \mathrm{L}$ of the resultant solution were applied to the target. Analytes were applied in amounts of 1 to $5 \mathrm{pmol}$ on the target using a matrix/analyte ratio of about 1:100.000. All compounds (Table 1) were purchased from Sigma-Aldrich (Deisenhofen, Germany) except 6, which was bought from Bachem (Bubendorf, Switzerland).

\section{Results and Discussion}

The H/D exchange of the protonated species for ten different peptides (Table 1), the gas-phase reaction of the protonated peptides with triethylamine as well as the dissociation by IRMPD of an observed protonbound heterodimer of triethylamine and 9 have been investigated using the altered MALDI source.

The structures of the peptides are shown in Scheme 1. Reaction series were performed with $\mathrm{CD}_{3} \mathrm{OD}$ for all peptides, and for Compounds 4 to 9 only H/D exchange reactions were also studied using $\mathrm{D}_{2} \mathrm{O}$.

\section{Results of $H / D$ Exchange Experiments}

The investigated peptides (Table 1) consist of different numbers of amino acid residues, thus their structures should display different reactivities in H/D exchange reactions. The goal was to investigate the H/D exchange reactions for this set of standard peptides in the external MALDI source at medium reaction pressures and compare these results with results previously reported from experiments carried out in the ICR cell [48, $60,61]$.

Angiotensin I (1), angiotensin II (2), angiotensin III (3) only differ by two and three residues, respectively: 2 only consists of the residues $1-8$ of the ten residues of angiotensin I (1) (i.e., His-Leu is missing at the C- 

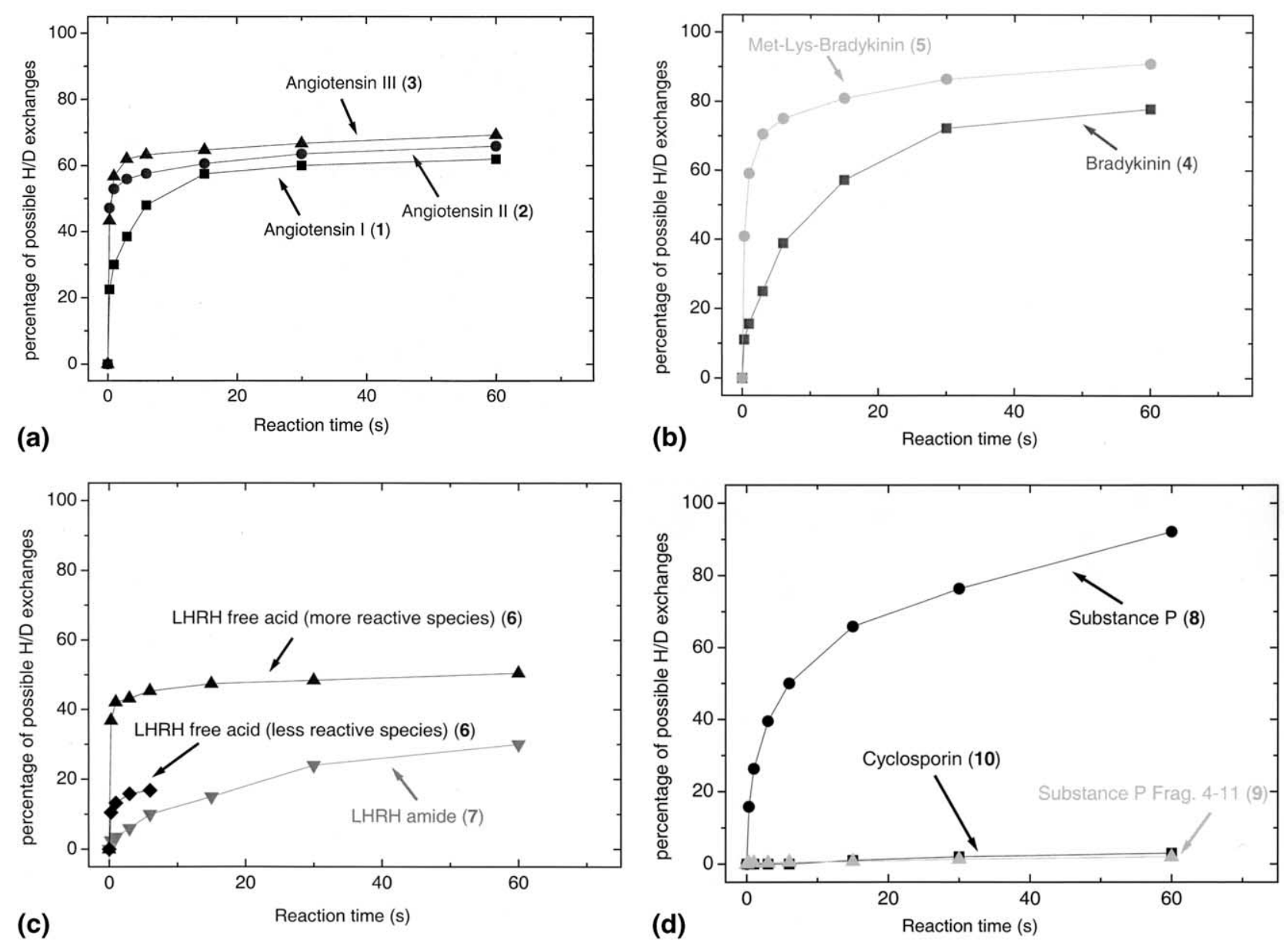

Figure 5. H/D exchange profiles for Compounds $\left([\mathbf{1}+\mathrm{H}]^{+}\right.$to $\left.[\mathbf{1 0}+\mathrm{H}]^{+}\right)$using deuterated reagent $\mathrm{CD}_{3} \mathrm{OD}$ at a reading pressure of $8.3 \times 10^{-6}$ mbar in the MALDI source. (a) $[\mathbf{1}+\mathrm{H}]^{+},[\mathbf{2}+\mathrm{H}]^{+}$, and $[3+\mathrm{H}]^{+} ;\left(\right.$b) $[4+\mathrm{H}]^{+}$and $[5+\mathrm{H}]^{+} ;\left(\right.$c) $[6+\mathrm{H}]^{+}$and $[7+\mathrm{H}]^{+} ;(\mathrm{d})[8+\mathrm{H}]^{+},[9+\mathrm{H}]^{+}$, and $[10+\mathrm{H}]^{+}$.

terminus), whereas angiotensin III (3) contains the residues 2-8 (i.e., compared to 1 His-Leu is missing at the C-terminus and Asp is missing at the N-terminus). $\mathrm{H} / \mathrm{D}$ exchange profiles of protonated 1-3 are expected to indicate differences in peptide structure as well as in peptide folding. Nevertheless, for all three types of angiotensins 1-3 H/D exchange with $\mathrm{CD}_{3} \mathrm{OD}$ of about $60 \%$ of the possible exchangeable $\mathrm{H}$-atoms has been observed. In Figure 4 the reaction of 1 with $\mathrm{CD}_{3} \mathrm{OD}$ at a pressure reading in the MALDI source of $8.3 \times 10^{-6}$ mbar is depicted. The H/D exchange profiles for the different types of angiotensins 1-3 are shown in Figure $5 \mathrm{a}$. Obviously, the difference in the H/D exchange profiles of $\mathbf{1}-\mathbf{3}$ can be ascribed a much faster reaction for the first few $\mathrm{H}$-atoms of 2 and 3 compared to $\mathbf{1}$. Therefore, the residues 9-10 (histidine and leucine) seem to hinder the fast H/D exchange of the first few acidic $\mathrm{H}$-atoms. It should be pointed out that all angiotensins 1-3 contain one arginine which is a very basic residue.

The comparison for the H/D exchange of bradykinin (4) and Met-Lys-bradykinin (5) is depicted in Figure 5b. The additional methionine and lysine at the N-terminus of 5 increase the reaction rate of the first few H/D exchanges. Also, with $\mathrm{CD}_{3} \mathrm{OD}$ as exchange reagent the percentage of possible $\mathrm{H} / \mathrm{D}$ exchanges after a reaction time of $60 \mathrm{~s}$ is more than $10 \%$ higher in 5 than in 4 . In contrast to this, the exchange with $\mathrm{D}_{2} \mathrm{O}$ yields rather similar results for the percentage of exchanged protons for 4 and 5 (Table 1). Nevertheless, with medium pressure conditions 4 rapidly exchanges $\mathrm{H}$-atoms to deuterium atoms. These results are in accordance with investigations by Wyttenbach et al. Using low pressure $\left(5 \times 10^{-6} \mathrm{mbar}\right)$ in-cell-H/D-exchange reactions Wyttenbach et al. also found the exchange of 15 out of 18 possible $\mathrm{H}$-atoms for bradykinin (4) after an extended reaction time of $2 \mathrm{~h}$ most likely via a relay mechanism $[61,62]$. These results are in contradiction to the studies by Freitas et al. [48]. The difference of the H/D exchange results by Wyttenbach and Freitas could be attributed to the thermalization of ions in the analyzer cell. During the experiments by Wyttenbach, ions have been thermalized by quadrupole axialization which could have result in ion excitation and a higher reaction rate of the $\mathrm{H} / \mathrm{D}$ exchange experiments. However, the excitation of ions has not been observed during the H/D exchange measurements in the hexapole of an ESI source by Hofstadler $[52,53]$. Although an ion excitation by RF $(2.3 \mathrm{MHz}$ and $\left.600 \mathrm{~V}_{p-p}\right)$ in the hexapole of the MALDI source is 


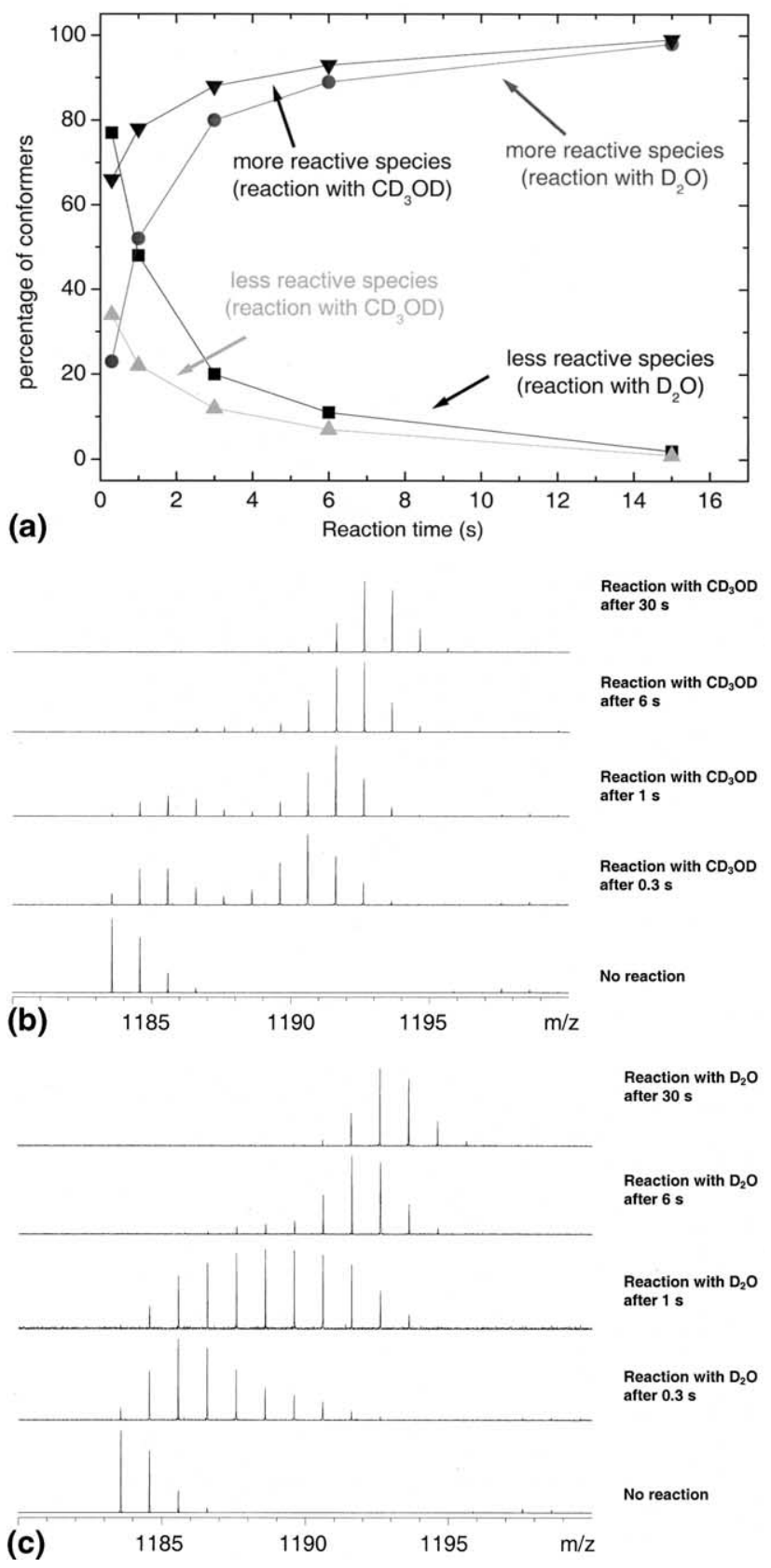

Figure 6. (a) Percentage of two gas-phase conformers of $[6+\mathrm{H}]^{+}$ after the reaction with $\mathrm{CD}_{3} \mathrm{OD}$ and $\mathrm{D}_{2} \mathrm{O}$. Spectra of the reaction of $[6+\mathrm{H}]^{+}$with $(\mathbf{b}) \mathrm{CD}_{3} \mathrm{OD}$ at a reading pressure of $8.3 \times 10^{-6}$ mbar, and (c) $\mathrm{D}_{2} \mathrm{O}$ at a reading pressure of $2.0 \times 10^{-6}$ mbar in the MALDI source. Two species with different efficiencies have been observed after the H/D exchange. possible, the reaction rates for the H/D exchange of peptides can be compared with each other as the same conditions were used in all experiments.

Ion-molecule reactions of luteinizing hormone-releasing hormone (LHRH) were investigated in the free acid (6) and amide form (7). Compared to Compounds 1 to 5 the overall percentage of H/D exchange is lower for the LHRH Compounds 6 and 7. Using medium pressure conditions two sets of peaks were observed during the exchange reactions of 6 indicating two gas-phase conformers with different reaction kinetics. Interesting in this context is the conversion of the apparently less reactive species (fast exchange of 3 $\mathrm{H}$-atoms) to the more reactive species (fast exchange of $8 \mathrm{H}$-atoms) during only the first $6 \mathrm{~s}$ of the measurement with the reaction gas $\mathrm{CD}_{3} \mathrm{OD}$ as well as $\mathrm{D}_{2} \mathrm{O}$ (Figure 6a). Two conformers of protonated LHRH free acid have not been observed in the H/D exchange studies by Freitas et al. [48], probably due to the much lower reaction gas pressure during experiments performed in the ICR cell. Therefore, very low reactive species using specific $H / D$ exchange reagents like $\mathrm{D}_{2} \mathrm{O}$ or $\mathrm{CD}_{3} \mathrm{OD}$ can be studied in combination with in-source ion-molecules reactions. Under low pressure conditions, e.g., in FT-ICR cells, $\mathrm{H} / \mathrm{D}$ exchange of very low reactive species can only be observed with the unspecific reagent $\mathrm{ND}_{3}$. The reaction with $\mathrm{CD}_{3} \mathrm{OD}$ resulted in separated patterns of peaks for short reaction times (Figure $6 \mathrm{~b}$ ). The reaction of 6 with $\mathrm{D}_{2} \mathrm{O}$ yields an identical isotopic pattern after $30 \mathrm{~s}$ of reaction, but compared to the reaction with $\mathrm{CD}_{3} \mathrm{OD}$ the distribution of peaks is broad after $1 \mathrm{~s}$ (Figure 6c). Despite the differences at the beginning of the $H / D$ exchange reaction of 6 with $\mathrm{D}_{2} \mathrm{O}$ and $\mathrm{CD}_{3} \mathrm{OD}$, after $6 \mathrm{~s}$ both systems seem to be dominated by the fast reaction only. For the amide 7 a different behaviour is revealed: It slowly exchanges $30 \%$ of the possible protons only and no separated or broad distribution of peaks is observed. This fact points strongly to the involvement of the c-terminal carboxy group in the fast H/D exchange of $\mathbf{6}$.

The possibility to distinguish gas-phase conformers by means of $\mathrm{H} / \mathrm{D}$ exchange, as in the case of 6 , has been described in detail for reactions in ICR-cells [63-66]. The reactions take place much longer in the ICR cell because of the relatively low pressure. In order to store ions efficiently for longer periods of time as needed for $\mathrm{H} / \mathrm{D}$ exchange studies, higher magnetic field strengths are favored. External ion-source ion-molecule reactions at medium pressures present an alternative to the in-cell

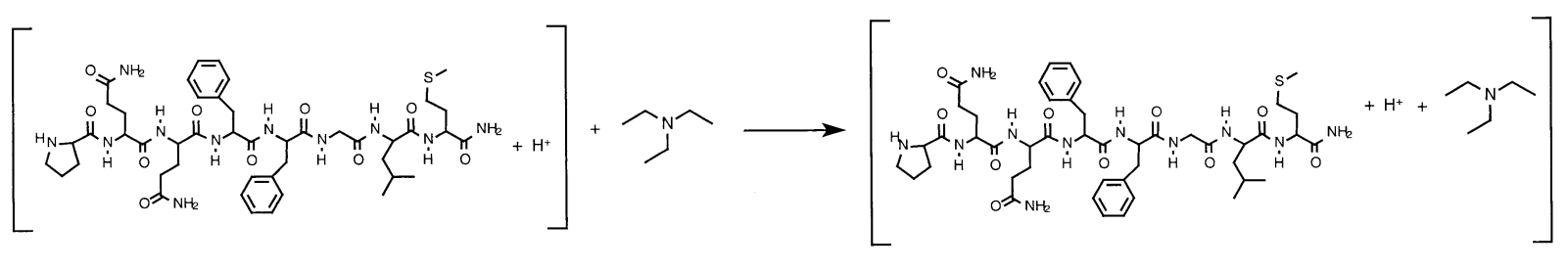

$[9+\mathrm{H}]^{+}$

$\left[9+\mathrm{H}+\mathrm{NEt}_{3}\right]^{+}$

Scheme 2 Formation of the proton-bound heterodimer $\left[9+\mathrm{H}+\mathrm{NEt}_{3}\right]^{+}$. 


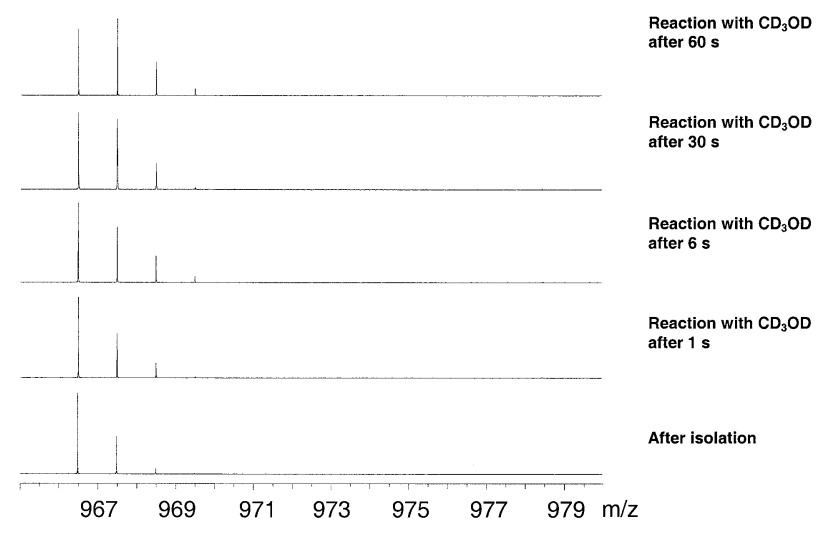

Figure 7. Reaction of $[9+\mathrm{H}]^{+}$with $\mathrm{CD}_{3} \mathrm{OD}$ at a reading pressure of $8.3 \times 10^{-6}$ mbar in the MALDI source after various reaction times.

reactions. Such investigations allow the option of using low magnetic field FT-ICR equipment since the ions are only captured and detected in the ICR cell and do not have to undergo ion-molecule reactions which would require a long trapping time.

The last set of investigated peptides consists of substance $\mathrm{P}(8)$, the truncated substance $\mathrm{P}$ fragment 4-11 (9), and the cyclopeptide cyclosporin A (10). The influence on the H/D exchange upon the presence of basic amino acids in the peptide sequence is demonstrated by the comparison of $\mathbf{8}, \mathbf{9}$, and $\mathbf{1 0}$ (Figure $5 \mathrm{~d}$ ). While 8 contains two basic amino acids (one Arg and one Lys) leading to an exchange of 19 out of 23 possible $\mathrm{H}$-atoms, neither $\mathbf{9}$ nor $\mathbf{1 0}$ have any basic amino acids present. Consequently, no H/D exchange is observed in the case of 9 and 10 (Figure 7).

\section{Results of Formation and Dissociation of a Proton- Bound Dimer}

The formation of a proton-bound heterodimer between the peptide substance P fragment 4-11 (9) and triethylamine could be observed (Scheme 2). 9 has the lowest proton affinity (PA) of all the peptides studied, because there are no basic residues (like arginine or lysine) present in 9. In accordance with that, no other protonbound heterodimer with triethylamine, which has an even lower PA, was observed. The reaction between 9 and triethylamine is fast compared to the H/D exchange experiments. After a reaction time of only $0.3 \mathrm{~s}$ with a reaction gas pressure of $6 \times 10^{-7} \mathrm{mbar} \mathrm{N}(\mathrm{Et})_{3}$ in the source area almost only the proton-bound complex was detected. The spectra resulting from various reaction times are shown in Figure 8. The existence of this complex was proven by its decomposition using IRMPD. The spectra of the decomposition of this complex with various irradiation times are depicted in Figure 9. The decrease of the peak intensity of the proton-bound dimer and the increase of the signal of protonated 9 is an evidence for the existence of a proton-bound complex between 9 and triethylamine. It

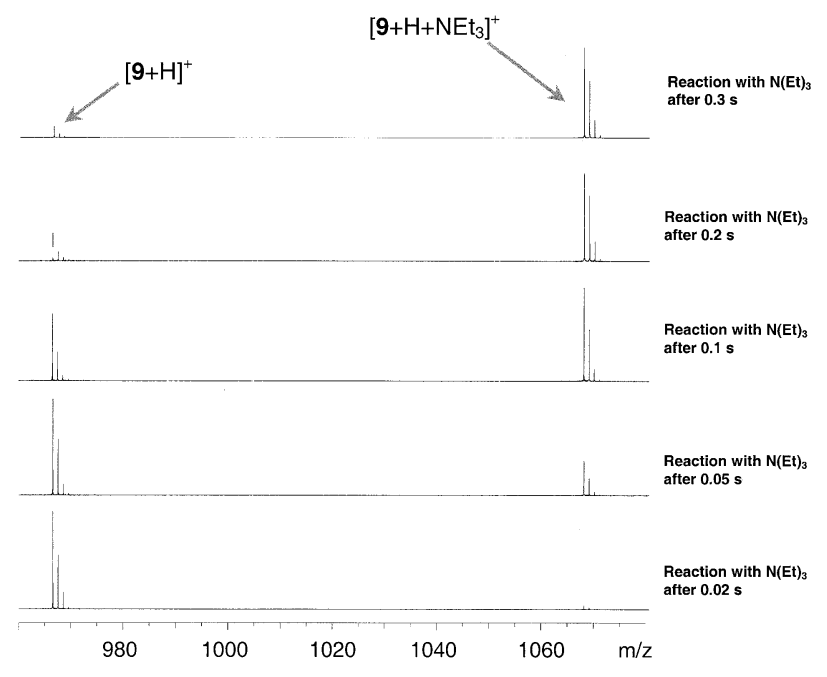

Figure 8. Reaction of $[9+\mathrm{H}]^{+}$with triethylamine $\left(\mathrm{NEt}_{3}\right)$ at a reading pressure of $6 \times 10^{-7} \mathrm{mbar}$ in the MALDI source after various reaction times.

can be assumed that 9 has a higher proton affinity than triethylamine because of the high peak intensity of protonated substance P fragment 4-11 (9) after the dissociation of the proton-bound complex by IR irradiation. This result has yet to be verified as the present work has focused at a much higher mass range than protonated triethylamine.

\section{Conclusion and Outlook}

The experiments described in this work show that thermalized ions generated in an external MALDI source and trapped in an in-source hexapole ion guide can undergo controlled gas-phase reactions, with the advantage of leaving the UHV of the analyzer cell undisturbed. Therefore, the high mass resolution is retained without any pumping delay which is usually necessary

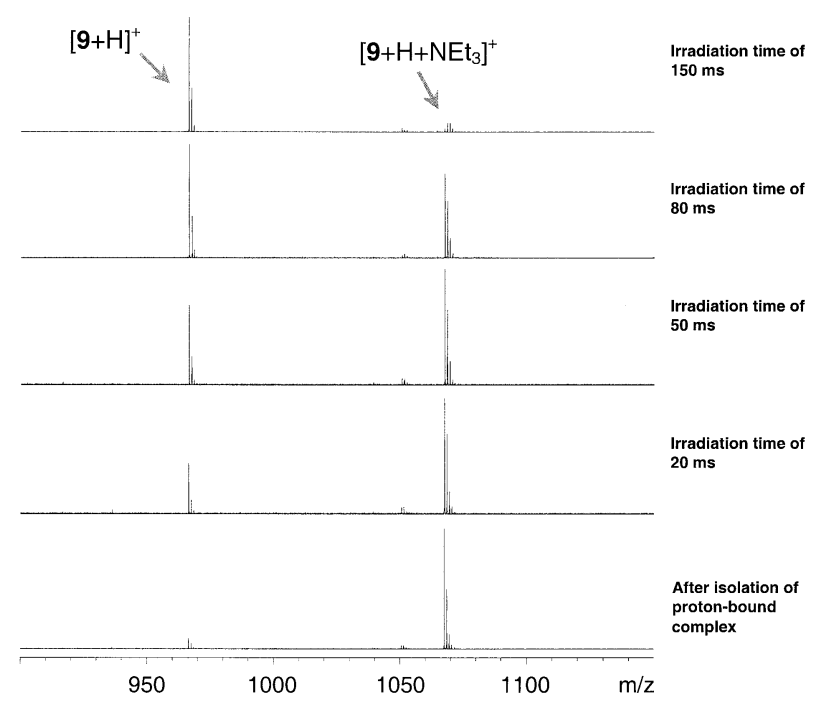

Figure 9. Dissociation of the proton-bound heterodimer $[9+\mathrm{H}$ $\left.+\mathrm{NEt}_{3}\right]^{+}$in the cell by IRMPD after various irradiation times. 
when reactions are carried out in the analyzer cell of a FT-ICR instrument. A pressure and time controlled H/D exchange of protonated peptides can be carried out in this ion source for structure and reactivity analysis of ions. Further, the opportunity to store ions in the multipole of the MALDI source is also interesting for experiments in which these ions can be irradiated by photons.

The experiments show that a MALDI source of this configuration is promising for the investigation of gasphase reactions of ions (especially peptides) generated by MALDI FT-ICR MS. An advantage of MALDI generated ions for ion-molecule reactions is the low sample amount (typically a few fmol) needed. Based on the preliminary work presented here, more gas-phase experiments will be carried out to further evaluate the advantages of this device in detail.

\section{Acknowledgments}

The authors would like to thank Gerhard Weiss, Christian Berg, and Jackie Jarvis for discussions and suggestions as well as Ralph Kikillus and Alfred Kraffert for their help in engineering.

\section{References}

1. Yamashita, M.; Fenn, J. B. Electrospray Ion Source. Another Variation on the Free-Jet Theme. J. Phys. Chem. 1984, 88, 4451-4459.

2. Yamashita, M.; Fenn, J. B. Negative Ion Production with the Electrospray Ion Source. J. Phys. Chem. 1984, 88, 4671-4675.

3. Fenn, J. B.; Mann, M.; Meng, C. K.; Wong, S. F.; Whitehouse, C. M. Electrospray Ionization for Mass Spectrometry of Large Biomolecules. Science 1989, 246, 64-71.

4. Kebarle, P.; Tang, L. From Ions in Solution to Ions in the Gas Phase. The mechanism of Electrospray Mass Spectrometry. Anal. Chem. 1993, 65, 972A-986A.

5. Kebarle, P. A Brief Overview of the Present Status of the Mechanisms Involved in Electrospray Mass Spectrometry. J. Mass Spectrom. 2000, 35, 804-817.

6. Hillenkamp, F.; Karas, M.; Beavis, R.; Chait, B. Matrix-Assisted Laser Desorption/Ionization Mass Spectrometry of Biopolymers. Anal. Chem. 1991, 63, 1193A-1203A.

7. Karas, M.; Bachmann, D.; Bahr, U.; Hillenkamp, F. MatrixAssisted Laser Desorption of Non-Volatile Compounds. Int. J. Mass Spectrom. Ion Processes 1987, 78, 53-68.

8. Karas, M.; Bahr, U.; Hillenkamp, F. UV Laser Matrix Desorption/ Ionization Mass Spectrometry of Proteins in the 100,000 Dalton Range. Int. J. Mass Spectrom. Ion Processes 1989, 92, 231-242.

9. Zenobi, R.; Knochenmuss, R. Ion Formation in MALDI Mass Spectrometry. Mass Spectrom. Rev. 1998, 17, 337-366.

10. Zaluzec, E. J.; Gage, D. A.; Watson, J. T. Matrix-Assisted Laser Desorption/Ionization Mass Spectrometry: Applications in Peptide and Protein Characterization. Prot. Exp. Purific. 1995, 6, 109-123.

11. Karbach, V.; Knochenmuss, R. Do Single Matrix Molecules Generate Primary Ions in UV MALDI? The Case of 2,5 Dihydroxybenzoic Acid. Rapid Commun. Mass Spectrom. 1998, 12, 968-974.

12. Burton, R. D.; Watson, C. H.; Eyler, J. R.; Lang, L. G.; Powell, D. H.; Avery, M. Y. Proton Affinities of Eight Matrices Used for Matrix-Assisted Laser Desorption/Ionization. Rapid Commun. Mass Spectrom. 1997, 11, 443-446.

13. Wong, C. K. L.; So, M. P.; Chan, T. W. D. Origins of the Proton in the Generation of Protonated Polymers and Peptides in Matrix-Assisted Laser Desorption/Ionization. Eur. Mass Spectrom. 1998, 4, 223-232.
14. Costello, C. E. Bioanalytic Applications of Mass Spectrometry. Current Opin. Biotechnol. 1999, 10(1), 22-28.

15. Marshall, A. G.; Hendrickson, C. L.; Jackson, G. S. Fourier Transform Ion Cyclotron Resonance Mass Spectrometry: A Primer. Mass Spectrom. Rev. 1998, 17, 1-35.

16. Marshall, A. G.; Grosshans, P. B. Fourier Transform Ion Cyclotron Resonance Mass Spectrometry: The Teenage Years. Anal. Chem. 1991, 63, 215A-229A.

17. Buchanan, M. V.; Hettich, R. L. Fourier Transform Ion Cyclotron Resonance Mass Spectrometry of High-Mass Biomolecules. Anal. Chem. 1993, 65, 245A-259A.

18. Amster, I. J. Fourier Transform Mass Spectrometry. J. Mass Spectrom. 1996, 31, 1325-1337.

19. Gross, M. L.; Rempel, D. L. Fourier Transform Mass Spectrometry. Science 1984, 226, 261-268.

20. Marshall, A. G. Milestones in Fourier Transform Ion Cyclotron Resonance Mass Spectrometry Technique Development. Int. J. Mass Spectrom. 2000, 200, 331-356.

21. Schiller, J.; Arnold, K. Mass Spectrometry in Structural Biology. In Mass Spectrometry in Structural Biology, Encyclopedia of Analytical Chemistry; Meyers, R. A., Ed.; John Wiley \& Sons Ltd: Chichester, 2000; pp 559-585.

22. Jungblut, P.; Thiede, B. Protein Identification from 2-DE Gels by MALDI Mass Spectrometry. Mass Spectrom. Rev. 1997, 16, 145-162.

23. Easterling, M. L.; Pitsenberger, C. C.; Kulnarni, S. S.; Taylor, P. K.; Amster, I. J. A 4.7 tesla Internal MALDI-FTICR Instrument for High Mass Studies: Performance and Methods. Int. J. Mass Spectrom. Ion Processes 1996, 158, 97-113.

24. Easterling, M. L.; Mize, T. H.; Amster, I. J. Routine ppm Mass Accuracy for High Mass Ions: Space-Charge Effects in MALDI-FT-ICR. Anal. Chem. 1999, 71, 624-632.

25. Köster, C.; Castoro, J. A.; Wilkins, C. L. High-Resolution Matrix-Assisted Laser Desorption/Ionization of Biomolecules by Fourier Transform Mass Spectrometry. J. Am. Chem. Soc. 1992, 114, 7572-7574.

26. Smith, E. T.; Cornett, D. S.; Amster, I. J.; Adams, M. W. W. Protein Molecular Weight Determinations by MALD Mass Spectrometry: A Superior Alternative to Gel Filtration. Anal. Biochem. 1993, 209, 379-380.

27. Nuwaysir, L. M.; Wilkins, C. L.; Simonsick, W. J., Jr. Analysis of Copolymers by Laser Desorption Fourier Transform Mass Spectrometry. J. Am. Soc. Mass Spectrom. 1990, 1, 66-71.

28. Castoro, J. A.; Wilkins, C. L. Ultrahigh Resolution MatrixAssisted Laser Desorption/Ionization of Small Proteins by Fourier Transform Mass Spectrometry. Anal. Chem. 1993, 65, 2621-2627.

29. McIver, R. T.; Li, Y.; Hunter, R. L. Matrix-Assisted Laser Desorption/Ionization with an External Ion Source FourierTransform Mass Spectrometer. Rapid Commun. Mass Spectrom. 1994, 8, 237-241.

30. McIver, R. T., Jr.; Li, Y.; Hunter, R. L. High Resolution Laser Desorption Mass Spectrometry of Peptides and Small Proteins. Proc. Natl. Acad. Sci. U.S.A. 1994, 91, 4801-4805.

31. Li, Y. Z.; Hunter, R. L.; McIver, R. T. Ultrahigh-Resolution Fourier Transform Mass Spectrometry of Biomolecules Above m/z 5000. Int. J. Mass Spectrom. Ion Processes 1996, 157/158, 175-188.

32. Green, M. K.; Medforth, C. J.; Muzzi, C. M.; Nurco, D. J.; Shea, K. M.; Smith, K. M.; Lebrilla, C. B.; Shelnutt, J. A. Application of MALDI-FTMS to the Analysis of Planar Porphyrins and Highly Substituted Nonplanar Porphyrins. Eur. Mass Spectrom. 1997, 3, 439-451.

33. Liu, J.; Tseng, K.; Lebrilla, C. B. A New External Ionization Multisample MALDI Source for Fourier Transform Mass Spectrometry. Int. J. Mass Spectrom. 2001, 204, $23-29$.

34. O'Connor, P. B.; Duursma, M. C.; van Rooji, G. J.; Heeren, R. M. A.; Boon, J. J. Correction of Time of Flight Shifted 
Polymeric Molecular Weight Distributions in Matrix-Assisted Laser Desorption/Ionization Fourier Transform Mass Spectrometry. Anal. Chem. 1997, 69, 2751-2755.

35. Heeren, R. M. A.; Boon, J. J. Rapid Microscale Analyses with an External Ion Source Fourier Transform Ion Cyclotron Mass Spectrometer. Int. J. Mass Spectrom. Ion Processes 1996, 157/158, 391-403.

36. Baykut, G.; Jertz, R.; Witt, M. Matrix-Assisted Laser Desorption/Ionization Fourier Transform Ion Cyclotron Resonance Mass Spectrometry with Pulsed In-Source Ion Accumulation. Rapid Commun. Mass Spectrom. 2000, 14, 1238-1247.

37. O'Connor, P. B.; Costello, C. E. A High Pressure MatrixAssisted Laser Desorption/Ionization Fourier Transform Mass Spectrometry Ion Source for Thermal Stabilization of Labile Biomolecules. Rapid Commun. Mass Spectrom. 2001, 15, 1862-1868.

38. He, F.; Ramirez, J.; Lebrilla, C. L. Evidence for Enzymatic Activity in the Absence of Solvent in Gas-Phase Complexes of Lysozyme and Oligosaccharides. Int. J. Mass Spectrom. 1999, 2/3, 103-114 193.

39. Lehmann, E.; Zenobi, R.; Vetter, S. Matrix-Assisted Laser Desorption/Ionization Mass Spectra Reflect Solution-Phase Zinc Finger Peptide Complexation. J. Am. Soc. Mass Spectrom. $1999,10,27-34$.

40. Schaaff, T. G.; Stephenson, J. L., Jr.; McLuckey, S. A. Gas-Phase H/D Exchange Kinetics: DI Versus $\mathrm{D}_{2} \mathrm{O}$. J. Am. Soc. Mass Spectrom. 2000, 11, 167-171.

41. Wang, F.; Li, W.; Emmett, M. R.; Hendrickson, C. L.; Marshall, A. G.; Zhang, Y. L.; Zhang, Z. J. Conformational and Dynamic Changes of yersinia Protein Tyrosine Phosphatase Induced by Ligand Binding and Active Mutation and Revealed by H/D Exchange and Electrospray Ionization Fourier Transform Ion Cyclotron Resonance Mass Spectrometry. Biochemistry 1998, 37, 15289-15299.

42. Ramanathan, R.; Gross, M. L.; Zielinski, W. L.; Layloff, T. P. Monitoring Recombinant Protein Drugs: A Study of Insulin H/D Exchange and Electrospray Ionization Mass Spectrometry. Anal. Chem. 1997, 69, 5142-5145.

43. Freitas, M. A.; Shi, S.D.-H.; Hendrickson, C. L.; Marshall, A. G. Gas Phase RNA and DNA Ions. 1. H/D-Exchange of the $(\mathrm{M}-\mathrm{H})$ Anions of Nucleoside 5'-mono-phosphate (GMP, dGMP, AMP, CMP, dCMP, UMP, dTMP), Ribose 5-Monophosphate, and 2-Deoxyribose 5-Monophosphate with $\mathrm{D}_{2} \mathrm{O}$ and $\mathrm{D}_{2}$ S. J. Am. Chem. Soc. 1998, 120, 10187-10193.

44. Dookeran, N. N.; Harrison, A. G. Gas-Phase H-D Exchange Reactions of Protonated Amino Acids and Peptides with $\mathrm{ND}_{3}$. J. Mass Spectrometry 1995, 30, 666-674.

45. Lee, S-W.; Lee, H-N.; Kim, H. S.; Beauchamp, J. L. Selective Binding of Crown Ethers to Protonated Peptides Can be Used to Probe Mechanisms of H/D Exchange and Collision-Induced Dissociation Reactions in the Gas Phase. J. Am. Chem. Soc. 1998, 120, 5800-5805.

46. Gard, E.; Willard, D.; Bregar, J.; Green, M. K.; Lebrilla, C. B. Site Specificity in the H-D Exchange Reactions of Gas-Phase Protonated Amino Acids with $\mathrm{CH}_{3} \mathrm{OD}$. Org. Mass Spectrom. 1993, 28, 1632-1639.

47. Wang, F.; Freitas, M. A.; Marshall, A. G.; Sykes, B. D. GasPhase Memory of Solution-Phase Protein Conformation: H/D Exchange and Fourier Transform Ion Cyclotron Resonance Mass Spectrometry of the N-Terminal Domain of Cadriac Troponin C. Int. J. Mass Spectrom. 1999, 192, 319-325.

48. Freitas, M. A.; Marshall, A. G. Rate and Extent of Gas-Phase Hydrogen/Deuterium Exchange of Bradykinins: Evidence for Peptide Zwitterions in the Gas Phase. Int. J. Mass Spectrom. 1999, 182/183, 221-231.

49. Campbell, S.; Rogers, M. T.; Marzluff, E. M.; Beauchamp, J. L. Deuterium Exchange Reactions as a Probe of Biomolecule Structure. Fundamental Studies of Gas Phase H/D Exchange Reac- tions of Protonated Glycine Oligomers with $\mathrm{D}_{2} \mathrm{O}, \mathrm{CD}_{3} \mathrm{OD}$, $\mathrm{CD}_{3} \mathrm{CO}_{2} \mathrm{D}$, and $\mathrm{ND}_{3}$. J. Am. Chem. Soc. 1995, 117, 12840-12854.

50. Green, M. K.; Gard, E.; Bregar, J.; Lebrilla, C. L. H-D Exchange Kinetics of Alcohols and Protonated Peptides: Effects of Structure and Proton Affinity. J. Mass Spectrom. 1995, 30, 1103-1110.

51. Akashi, S.; Naito, Y.; Takio, K. Observation of HydrogenDeuterium Exchange of Ubiquitin by Direct Analysis of Electrospray Capillary-Skimmer Dissociation with Fourier Transform Ion Cyclotron Resonance Mass Spectrometry. Anal. Chem. 1999, 71, 4974-4980.

52. Hofstadler, S. A.; Sannes-Lowery, K. A.; Griffey, R. H. Enhanced Gas-Phase Hydrogen-Deuterium Exchange of Oligonucleotide and Protein Ions Stored in an External Multipole Ion Reservoir. J. Mass Spectrometry 2000, 35, 62-70.

53. Hofstadler, S. A.; Sannes-Lowery, K. A.; Griffey, R. H. Infrared Multiphoton Dissociation in an External Ion Reservoir. Anal. Chem. 1999, 71, 2067-2070.

54. Smith, D.; Adams, G. Bowers, M. T., Ed. Gas Phase Ion Chemistry, Vol. I. Academic Press: New York, San Francisco, London, 1979; Chap I, pp 2-44.

55. Hofstadler, S. A.; Sannes-Lowery, K. A.; Griffey, R. H. A Gated-Beam Electrospray Ionization Source with an External Ion Reservoir. A New Tool for Characterization of Biomolecules Using Electrospray Ionization Mass Spectrometry. Rapid Commun. Mass Spectrom. 1999, 13, 1971-1976.

56. Sannes-Lowery, K.; Griffey, R. H.; Kruppa, G. H.; Speir, J. P.; Hofstadler, S. Multipole Storage Assisted Dissociation, a Novel In-Source Dissociation Technique for Electrospray Ionization Generated Ions. Rapid Commun. Mass Spectrom. 1998, 12, 1957-1961.

57. Axelsson, J.; Håkansson, K.; Palmblad, M.; Håkansson, P. Electron Capture Dissociation of Substance P Using a Commercially Available Fourier Transform Ion Cyclotron Resonance Mass Spectrometer. Rapid Commun. Mass Spectrom. 1999, 13, 1550-1552.

58. Håkansson, K.; Axelsson, J.; Palmblad, M.; Håkansson, P. Mechanistic Studies of Multipole Storage Assisted Dissociation. J. Am. Soc. Mass Spectrom. 2000, 11, 210-217.

59. Caravatti, P.; Allemann, M. "The Infinity Cell": A New Trapped-Ion Cell with Radiofrequency Covered Trapping Electrodes for Fourier Transform Ion Cyclotron Resonance Mass Spectrometry. Org. Mass Spectrom. 1991, 26, 514-518.

60. Freitas, M. A.; Hendrickson, C. L.; Emmett, M. R.; Marshall, A. G. High-Field Fourier Transform Ion Cyclotron Resonance Mass Spectrometry for Simultaneous Trapping and Gas Phase Hydrogen/Deuterium Exchange of Peptide Ions. J. Am. Soc. Mass Spectrom. 1998, 9, 1012-1019.

61. Wyttenbach, T.; Bowers, M. T. Gas-Phase Conformations of Biological Molecules: The Hydrogen/Deuterium Exchange Mechanism. J. Am. Soc. Mass Spectrom. 1999, 10, 9-14.

62. Wyttenbach, T.; von Helden, G.; Bowers, M. T. Gas-Phase Conformation of Biological Molecules: Bradykinin. J. Am. Chem. Soc. 1996, 118, 8355-8364.

63. Wood, T. D.; Chorush, R. A.; Wampler, F. M.; Little, D. P.; O'Connor, P. B.; McLafferty, F. W. Gas-Phase Folding and Unfolding of Cytochrome c Cations. Proc. Natl. Acad. Sci. U.S.A. 1995, 92, 2451-2454.

64. McLafferty, F. W.; Guan, Z.; Haupts, U.; Wood, T. D.; Kelleher, N. L. Gaseous Conformational Structures of Cytochrome c. J. Am. Chem. Soc. 1998, 120, 4732-4740.

65. Carr, S. R.; Cassady, C. J. Elucidation of Isomeric Structures of Ubiquitin Ions Produced by Electrospray Ionization Mass Spectrometry. J. Mass Spectrom. 1996, 31, 247-254.

66. Freitas, M. A.; Hendrickson, C. L.; Emmett, M. R.; Marshall, A. G. Gas-Phase Bovine Ubiquitin Cation Conformation Resolved by Gas-Phase Hydrogen/Deuterium Exchange Rate and Extent. Int. J. Mass Spectrom. 1999, 185/186/187, 565-575. 